\title{
PETER JAGERS: A COLLEGIAL PERSPECTIVE
}

\author{
BY OLLE NERMAN
}

From the day in early autumn 1972 that I stepped into the office of Professor Harald Bergström and asked permission to become a $\mathrm{PhD}$ student in mathematical statistics at the University of Gothenburg, Peter Jagers has been very important in my life and career. He gave the first graduate course that I attended, a wonderful and carefully designed series of detailed lectures on branching processes, while he simultaneously wrote his now classical Wiley book Branching Processes with Biological Applications. He was at that time a young successful reader (docent) in mathematical statistics at the joint Department of Mathematics of Chalmers University of Technology and University of Gothenburg. And he was already supervising a handful of graduate students. The now well-known professors Torgny Lindvall and Anders Grimvall were among them. Professor Olav Kallenberg, although not formally supervised by Peter, was also greatly inspired by him in his choice of research directions and topics in his graduate studies.

The mathematical foundation and many basic results on Crump-Mode-Jagers branching processes (or, as Peter named them, general branching processes) were in place, much thanks to him. He had also contributed to the mathematical foundations of point processes and random measures, and already started his long engagement with scientific societies both in Sweden and internationally. Peter had valuable experience from a research period, facilitated by a bi-national cultural exchange programme, in Moscow State University during his graduate studies. There he was taken care of by Professor Prokhorov and had valuable inspiration from Professor Boris Sevastyanov and his research team in his struggle to develop the mathematics of general branching processes. Peter's graduate studies resulted in an excellent $\mathrm{PhD}$ thesis and an exam in 1968. And when I started he was back from a successful Assistant Professor position in Stanford in the academic year 1970/71. Already, he was a hot candidate to succeed his graduate supervisor Professor Harald Bergström, who was soon to retire. A year or so later I had changed supervisor from retiring Harald to Peter, and branching processes would dominate my research as well in the next two decades.

Like many other things in life, Peter's initial interest in branching processes was slightly random and originated from the fact that he got his eyes on, and started to study, Ted Harris's then novel branching process book, rather than at the direction of Harald.

\section{Early years}

Peter was born in March 1941 in Gothenburg. His mother and father had left Vienna in Austria before the Second World War. His father was a chemist associated with Chalmers; later he was also a college teacher, and Peter grew up in the urban district Johanneberg, in the immediate neighbourhood of the main campus of Chalmers. When he was in his mid-teens, the whole family spent a year in Benares (Varanasi) in India where his father held a guest professor position at the university. Peter did not study much science or mathematics in high school, but oriented towards languages, including Latin, and various humanistic subjects, and he did his, at that time obligatory, military service by training to become an interpreter from several languages, including Russian. Following his military service, in 1960 he started studies at the 
University of Gothenburg. In this setting he first really became interested in mathematics and statistics when he studied logic in philosophy and political economy at an undergraduate level and found the basic foundations in the latter course somewhat sloppily described and not very logical.

Thus, in Peter's mind, mathematics is mainly a powerful precise language which can be used to understand the real world better, and the study of mathematical models is a somewhat idealised way of thinking about the physical world. Formulae and theorems are just other words for precise sentences, and should thus be an integrated part of the texts in the writing of mathematics. His humanistic background and skills are also manifest in his scientific texts in that these are, for a mathematician whose mother-tongue is not English, unusually literary in their style (to paraphrase a reviewer of his Wiley book).

The balance between idealisation and model complexity is very important to him, and the roles of stochastic models are in most of his work more in the tradition of yet another sophisticated mathematical deduction tool, rather than just a basis for empirical statistical conclusions. He prefers generality: unnecessary oversimplification is not his cup of tea. A not so serious consequence of his unusual early career is that there are certain blind spots in his basic mathematical training, so, for example, the use of trigonometric formulae is not his strongest suit.

All students he supervised over the years, including myself, are extremely thankful for his invaluable help in our struggle to structure our axioms, theorems, and conclusions, and to find appropriate words and phrases. Following Peter's advice has resulted in texts that are not endless sequences of formulae, but readable, length-balanced, coherent, and logically precise mixtures of mathematical arguments and verbal descriptions of the problems treated, and of general conclusions drawn from the results.

\section{Career}

Peter received the chair in mathematical statistics at Chalmers University of Technology in 1974, at the age of only thirty-three. He quickly became a well-liked, open-minded, scientific leader of the division. At that time the unit was small enough to be run in a direct democratic way, with all faculty and graduate students in mathematical statistics meeting regularly to discuss curricula, seminars, allocation of courses, labs, exercises, etc. Often these meetings, and many dinners after guest seminars, took place in the evenings in Peter's home or in his garden, conveniently situated a short walk from the department. Peter and his wife Solveig, at the time an architecture graduate student, prepared excellent food, while their charming young daughter Lisa helped in entertaining us guests.

\section{Peter and me}

There was also a statistical consulting group at the department, focusing mainly on medical statistics and probability modelling and statistics in science. This group contributed greatly to the variety of discussions and seminars. Among the many topics that Peter gave long series of seminars on, primarily meant for us graduate students, I remember, and appreciated, the foundations of inference seminars in the mid 1970s. These seminars were full of enthusiastic discussions about all kinds of likelihood, sufficiency, ancillarity, invariance, and completeness principles that you can imagine, a true paradise for us students. I think he, and we all, were partly inspired, in this effort to become more inference oriented, by scientists in the theoretical statistics division at Copenhagen University, Ole Barndorff-Nielsen, Sören Johansen, and others. I also think that it was in connection to this inference foundation course that Peter's interest in the sample survey area arose. He led a small research group of graduate students a couple of years 
in the 1980s focusing mainly on post-stratification techniques and large sample approximations of distributions of various sampling statistics. During this period, he also became a member of the statistical advisory board of Statistics Sweden (SCB), where he served for more than twenty years.

The first years after my dissertation I stayed in the department on temporary positions and continued to collaborate with Peter, and we wrote a series of papers together concerning compositions of general branching populations. It was a true pleasure both to be supervised by Peter and then to interact with him on a slightly more collegial level during these years. I remember the two of us sitting under an apple tree in full bloom in his garden, discussing and writing about some asymptotic properties of supercritical branching processes. In the years around 1990 we also co-supervised a group of PhD students; Per Broberg, Ziad Taib, and the talented but shy, student Torbjörn Jönsson. Torbjörn revitalized Peter's and my interest in cell cycle modelling and biological modelling in general. With his serious attitude and mathematical talent and ideas, he was an inspiration for both of us, the moreso after he tragically passed away after a short illness in ALS at just around thirty years of age. Ziad stayed with the department around fifteen years before leaving for the pharmaceutical industry, but has maintained his association with the department as an adjoint professor.

\section{Day care centre}

On the personal side I am also very grateful to Peter because of his timely foundation of a cooperative day care centre in the early 1980s. There was a severe shortage of childcare facilities in Gothenburg, and Peter and Solveig's young child Jonas was surrounded by neighbouring young children with desperate parents. My wife Anne was just finishing her preschool teacher training. An idyllic, small cooperative day care centre was planned and started in a rented part of a fairly new building, owned by a local scout society, about 100 metres from Peter's house. Parents prepared food and kept the facilities clean and tidy, while Anne had the opportunity to try her freshly-learned theories in praxis together with a couple of other teachers. Peter chaired the board and ran all the bureaucracy swiftly and efficiently, as always. In later years Jonas studied the mathematical engineering programme at Chalmers (he has contributed to this Festschrift with a paper co-authored with Professor Serik Sagitov).

\section{Student union and politics}

As an undergraduate and graduate student, Peter was heavily engaged in the student union. Besides his academic engagements, he was an active, quite radical, member of the Social Democratic Party. I think that part of his radicalism came from the somewhat shocking experience of poverty and class difference that he saw in his teenage year in India. The former Swedish prime minister Olof Palme, with his genuine international engagement for under-privileged people and his Vietnam war engagement, was somewhat of an ideal for many young men and women in his generation, and to some degree that was also true for Peter.

I am convinced that Peter could have made a national political career had he wanted to, but his early success in academia made him hard to recruit. Instead he became engaged in local traffic policy groups and traffic related city boards, fighting for preservation of the Gothenburg tram system (still functioning today), and against too many cars in the city centre by stopping plans to build giant underground garages, etc. These successes were not without opposition in his Party. After all, the car, lorry, and bus giant Volvo was, and still is, very important to Gothenburg where the Party was a dominant political player during these years. In later years he has been less politically active, but always very interested in politics. 
A consequence of these union- and committee-engagements is that Peter is an excellent chairperson of meetings. Another consequence is that he really favours compromise over conflict, as when it comes to academic fights for grants, in local academic funding conflicts, and in issues of balance of disciplinary impact through representations in key boards and committees.

\section{Stochastic processes conference}

In 1984 Peter headed the local organisation committee for the Fourteenth Conference of Stochastic Processes and their Applications (SPA) which was hosted by the division and took place at the Chalmers campus. Professors Ito, Doob, Leadbetter, and Cramér among many others gave invited plenary talks, and the conference was very successful. In June 2018 the Fortieth SPA conference was again held in Gothenburg with Peter again assisting, but this time Professor Sergei Zuyev led the local organisation.

Peter is a very efficient organizer, and leader of organisational work. He trusts the members in his teams and knows how to balance available competence and needs. He never panics in case of urgent practical problems and instead sorts them out rapidly and adequately. It has always been a pleasure to work in different departmental roles and in committees that he has led.

\section{Collaborations and guests}

Peter had a large scientific contact network early on, and his knowledge of the mathematical statistics research and scientists behind the Iron Curtain benefitted the department with a steady stream of statistical and probability scholars visiting from Moscow, Leningrad, Berlin, Romania, DDR, and Hungary in the 1970s and 1980s.

In the mid 1980s Peter established close contacts with the research groups in population dynamics around the Dutch professors Odo Diekmann and Hans Metz. These groups were at that time using large population dynamical models, in which randomness was approximated away, and used and developed dynamical systems models. In these Peter's speciality, renewal theoretical arguments, were not obvious, but potentially important tools. These contacts led Peter to fruitful long-time research collaborations with Hans Metz and Patsy Haccou in Leiden and with Mats Gyllenberg, nowadays in Helsinki.

At roughly the same time Peter and I were invited together to Paris to visit Professor Neveu who led a group of theoretical researchers interested in branching processes. In particular, his young $\mathrm{PhD}$ student Brigitte Chauvin studied foundations of branching processes partly inspired by Peter's results and results in my thesis. And later Peter maintained contact with many more French branching process specialists. Peter has also collaborated and co-published joint research with the French biomathematician Christine Jacob in 2004 on polymerase chain reaction modelling using branching processes.

From the late 1980s Harry Cohn at Melbourne University and his former student Fima Klebaner started collaboration with Peter's group; Peter's collaboration with Fima has intensified over the years. They have written many joint papers about size-dependent branching processes in the last fifteen years. Peter has also been a regular guest researcher at Monash University in Melbourne and Fima has spent several sabbatical research periods at Chalmers.

Contacts with the Moscow School of Branching Processes were revitalised after the first Bernoulli conference in Tashkent in 1987. Interactions with Professor Vladimir (Volodya) Vatutin, his research group, and colleagues have been regular and important over the years. Professor Serik Sagitov, now head of the applied mathematics and statistics division of the 
Mathematics Department of Chalmers and Gothenburg University, was supervised by Volodya in his PhD studies. Serik and Peter have done research together in various population dynamics topics over the years and kept the branching research tradition spirit alive in Gothenburg. Volodya, Peter, and Patsy Haccou together were the main authors of the 2005 Cambridge University Press book Branching Processes: Variation Growth and Extinction of Populations.

Vital interactions over the years with branching specialists in Australia, USA, UK, Germany, Ukraine, etc. have also resulted in many visits and guest lectures by, e.g. Chris Heyde, Eugene Seneta, Krishna Athreya, Peter Ney, Anatole Joffe, Valentin Shurenkov, John Biggins, Andrew Barbour, Klaus Fleichmann, Götz Kersting, Anton Wakolbinger, Gerold Alsmeyer, Don Dawson, Peter Donnelly, Simon Tavaré, and many more. From Denmark, at first Niels Keiding and later Sören Asmussen were natural collaborators, and Sören was a long-term research guest and teacher at the department in the early 1990s.

Peter has kept visiting and helped individuals as well as groups of Indian, Bulgarian, Spanish, and Portuguese probabilists to establish research in branching processes and population dynamics in general. He was awarded an honorary doctor's degree from the Bulgarian Academy of Science in 2000 on the initiative of Professor Nicolas Yanev. Peter also suggested and hosted both Professors Ted Harris and Boris Sevastyanov as honorary doctors in Chalmers.

\section{Supervisor and more}

I have already mentioned some of Peter's graduate students, but there are many more. In particular, I would like to mention my contemporary colleagues Arne Ran, Martin Härnqvist, and Björn Rosander, who all left for successful industrial work. Other examples are Professors Anders Odén, a long-term practising medical statistician in Gothenburg and Peter Olofsson, recently appointed at University of Jönköping Sweden after a career of almost two decades in USA, and there are about a dozen more if one also counts the licentiate degree students.

In 1989-1993 Peter was the main editor of the journal Stochastic Processes and Their Applications, and has been associated and coordinating editor in several international journals. He has refereed regularly for the most important journals in probability, stochastic processes, biostatistics, and biomathematics. He has served in a wide range of national and international boards and committees for dissertations, journals, conferences, and evaluations of national mathematical and statistical research programmes, etc. For example, he was President of the Bernoulli Society in 2005-2007.

In his early years Peter was a member of the University of Gothenburg board. For some years, he was also head of the section of mathematics and computer science (dean) in Chalmers and University of Gothenburg. And for many years around the turn of the century he chaired the Chalmers Faculty Senate and was an appreciated member of Chalmers board.

\section{Stochastic centre}

In the mid 1990s, Peter together with Professors Holger Rootzén and Sture Holm, and others, initiated a broad application for the funding of research and collaboration in probability and statistics. This effort was successful and for around ten years the Gothenburg Stochastic Centre was a well-funded, important resource at the department led by Peter and run by Professor Mats Rudemo. It arranged thematic semesters with guests, workshops, financed graduate students and facilitated novel research initiatives at a scale that we had earlier only dreamt of. These were the times when areas like material fatigue statistics, genetic epidemiology, statistical imaging, applied extreme value theory in insurance and finance, and bioinformatics were established as vital research areas in the department. 


\section{More quantitative biology}

Personally, I am also very grateful to Peter for his engagement in Chalmers Bio initiative and the large Gothenburg/Lund based Wallenberg foundation funded academic research project, SWEGENE, around the turn of the century. He was a board member of the SWEGENE consortium and he encouraged me to reorient my research towards statistical applications in bioinformatics and genomics, and to engage heavily in masters, graduate, and postdoc research training in bioinformatics.

Somewhat later, in 2001, he played a key role in establishing the Fraunhofer-Chalmers Research Centre for Industrial Mathematics (FCC), Gothenburg. He also represented Chalmers and the department and chaired the FCC board for many years.

\section{Swedish and local academies}

Already in 1978 Peter was invited to be a member of the Royal Society of Arts and Science, a local academy in Gothenburg, and he was for a period president of this academy. In 1989 he was selected to be a member of the Swedish Royal Academy of Sciences, mathematics division. In the period 2007-2010 he was its first vice president. This prestigious society among other activities awards Nobel prizes in physics and chemistry and the Swedish National Bank's Prize in Economic Sciences in Memory of Alfred Nobel.

\section{Time sharing capacity}

In mathematics, we are accustomed to seeing bright superstars who produce important research reports and interesting results at a very fast speed. They simply seem to have a special talent for numbers and logical reasoning and quite often combine that with a nerd personality. But the talent of running departments, organisations, journals, supervision, and teaching, simultaneously with such research, is much rarer. So Peter serves as an existence theorem: in my work life I have never met anyone else who can get in and out in his research activity as easily and efficiently as Peter. Ten minutes here, a quarter of an hour there, and at the end of the day he is ready to deliver a new version of a manuscript to his collaborator.

\section{Two symposia in honour of Peter}

In 2008, when Peter passed the Swedish default retirement age of 67, we organized a symposium to honour him in Gothenburg. It was a successful mixture of great science, nostalgia, and excellent festivities. In 2017 some of us again visited a conference in honour of Peter and Fima Klebaner at the Monash University research station in Prato outside Firenze in Italy. I can assure you that this meeting too was a great success, and some of the papers in this issue are based on or related to the talks given in that symposium.

\section{In summary}

Peter Jagers is an unusually, universally gifted person who has worked very hard in a very long, and equally successful academic career. He has contributed excellent research and supervision. He has served communities of mathematicians and other scientists nationally and internationally far more than one usually expects from a typical scientist.

I am roughly ten years younger than Peter. I have just retired from Chalmers and look forward to some lazy years, probably with some scientific hobby projects between periods of gardening, travel and grandchildren duties. But Peter and many other colleges in the older 
generation (e.g. Mats Rudemo and Holger Rootzén in the same department) have still not relaxed. Peter, Mats, and Holger just continue their research activities at full speed. Thus, it must be an almost optimal choice to let mathematics, probability, and statistics drive your professional life. I hope that after some period of much needed relaxation I can follow in their footsteps and keep contributing to the subject we all love so much.

Thank you Peter for all you have done for me, my family, my colleagues, the department, Chalmers and University of Gothenburg, probability, statistics and biomathematics disciplines and communities, and for the science community in general. 